Virginia Commonwealth University vCU Scholars Compass

2010

\title{
Alcohol problems in young adults transitioning from adolescence to adulthood: The association with race and gender
}

\author{
Karen G. Chartier \\ Virginia Commonwealth University, kgchartier@vcu.edu \\ Michie N. Hesselbrock \\ University of Connecticut School of Medicine and Dentistry \\ Victor M. Hesselbrock \\ University of Connecticut School of Medicine and Dentistry
}

Follow this and additional works at: http://scholarscompass.vcu.edu/socialwork_pubs

Part of the Gender and Sexuality Commons, Race and Ethnicity Commons, Social Work Commons, and the Substance Abuse and Addiction Commons

(C) 2010, Elsevier. Licensed under the Creative Commons Attribution-NonCommercial-NoDerivatives 4.0 International (http://creativecommons.org/licenses/by-nc-nd/4.0/). This is the author's version of a work that was accepted for publication in Addictive Behaviors 36(3): 167-174, March 2011. The final publication is available at http://dx.doi.org/ 10.1016/j.addbeh.2010.10.007.

\section{Downloaded from}

http://scholarscompass.vcu.edu/socialwork_pubs/13

This Article is brought to you for free and open access by the School of Social Work at VCU Scholars Compass. It has been accepted for inclusion in Social Work Publications by an authorized administrator of VCU Scholars Compass. For more information, please contact libcompass@vcu.edu. 


\title{
Alcohol problems in young adults transitioning from adolescence to adulthood: The association with race and gender
}

\author{
Karen G. Chartier, Ph.D. ${ }^{a}$ [Faculty Associate], Michie N. Hesselbrock, Ph.D. ${ }^{\text {[Professor], }}$ \\ and Victor M. Hesselbrock, Ph.D. [Professor and Interim Chairman] \\ a University of Texas School of Public Health, Dallas, Texas \\ b Department of Psychiatry, University of Connecticut School of Medicine, Farmington, \\ Connecticut \\ c Department of Psychiatry, University of Connecticut School of Medicine, Farmington, \\ Connecticut
}

\begin{abstract}
Race and gender may be important considerations for recognizing alcohol related problems in Black and White young adults. This study examined the prevalence and age of onset of individual alcohol problems and alcohol problem severity across race and gender subgroups from a longitudinal study of a community sample of adolescents followed into young adulthood ( $N=166$; 23-29 yrs. old who were drinkers). All alcohol problems examined first occurred when subjects were in their late teens and early 20s. Drinking in hazardous situations, blackouts, and tolerance were the most common reported alcohol problems. In race and gender comparisons, more males than females experienced alcohol problems. Blacks generally had a later age of onset of alcohol problems. Multivariate regressions showed greater alcohol problem severity in males compared to females, but no significant differences between Blacks and Whites. Education, family environment and earlier alcohol use behaviors and expectancies were reliable predictors of alcohol problem severity in young adulthood. White males were at particular risk for experiencing more severe alcohol problems. Findings may inform the design of more targeted interventions for alcohol problems in different populations.
\end{abstract}

\section{Keywords}

Alcohol; alcohol problems; race; gender; adolescents; young adults

\section{Introduction}

In its most recent Strategic Plan, the National Institute on Alcohol Abuse and Alcoholism (NIAAA, 2008) endorses a lifespan perspective for examining the characteristics and

\footnotetext{
Corresponding author: ${ }^{\mathrm{c}}$ Victor M. Hesselbrock, Department of Psychiatry, School of Medicine, University of Connecticut, 263 Farmington Avenue, MC-2103, Farmington, CT 06030, 860-679-3266 (phone); 860-679-4077 (fax), , Hesselbrock@uchc.edu. Additional authors: ${ }^{a}$ Karen G. Chartier, Ph.D., School of Public Health, University of Texas, 5323 Harry Hines Boulevard, V8.112, Dallas, TX 75390, 214-648-6574 (phone); 214-648-1081 (fax), Karen.Chartier@UTSouthwestern.edu

$\mathrm{b}$ Michie N. Hesselbrock, Ph.D. Department of Psychiatry, School of Medicine, University of Connecticut, 263 Farmington Avenue, MC-2103, Farmington, CT 06030, 860-679-3708 (phone); 860-679-4077 (fax), Mhesselbrock@uchc.edu

Publisher's Disclaimer: This is a PDF file of an unedited manuscript that has been accepted for publication. As a service to our customers we are providing this early version of the manuscript. The manuscript will undergo copyediting, typesetting, and review of the resulting proof before it is published in its final citable form. Please note that during the production process errors may be discovered which could affect the content, and all legal disclaimers that apply to the journal pertain.
} 
consequences of drinking behaviors at different stages of development. In this study we prospectively examined individual alcohol related problems and alcohol problem severity in Black and White young adults. Alcohol use behaviors typically change over time, particularly during the transition period from adolescence to adulthood. Adolescence includes the peak years for the initiation of drinking (i.e., ages 13-14) (Faden, 2006). Rates of alcohol use and intoxication increase during adolescence and continue to rise in the years after high school (Brown, et al., 2008; O'Malley, Johnston, \& Bachman, 1998).

Epidemiological studies demonstrate a peak for alcohol use and heavy drinking in late adolescence and early adulthood, as well as the incidence and prevalence of alcohol abuse and dependence (Chen, Dufour, \& Yi, 2004/2005; Harford, Grant, Yi, \& Chen, 2005). Not surprisingly, symptoms of alcohol abuse and dependence frequently first appear in mid- to late adolescence, approximately $40 \%$ of persons with alcohol use disorders developed their first symptoms between ages $15-19$ (Martin \& Winters, 1998).

\subsection{Differences in alcohol use behaviors by race and gender}

Alcohol use behaviors do vary by sociodemographic characteristics such as race and gender. For example, the 1991-2007 rates of underage drinking are highest for Whites, followed by Hispanics and then Blacks (Chen, Hsiao-ye, Williams, \& Faden, 2009). Across this time period, males had a higher average frequency, quantity, and volume of past 30-day drinking than females. In a national sample of young adults from the National Epidemiologic Survey on Alcohol and Related Conditions (NESARC), Whites compared with Blacks had a higher prevalence of both drinking and exceeding the recommended daily and weekly drinking limits (Chen, et al., 2004/2005). Daily limits were specified as consuming more than 4 drinks in a single day for men and more than 3 drinks in a single day for women; weekly limits involved consuming on average more than 2 drinks per day for men and more than 1 drink per day for women. Compared with females, more males exceeded the recommended daily and weekly alcohol limits (Chen, et al., 2004/2005). The 2006 National Survey on Drug Use and Health (NSDUH) also reported higher rates of 30-day binge and heavy drinking for males than females ages $18-25(50.2 \%$ and $21.0 \%$ versus $43.0 \%$ and $10.0 \%$, respectively; SAMHSA, 2007)

Similar to drinking behaviors, individual alcohol use disorder symptoms and related problems appear to vary according to race and gender. However, few studies have examined these subgroup differences, particularly among adolescents and young adults (Wagner, Lloyd, \& Gil, 2002). Several studies of older adults have tested race and gender differences in the prevalence and age of onset of alcohol problems using retrospective subject reports. Adult males generally report a higher prevalence of individual alcohol problems (e.g., alcohol-related violence, driving while intoxicated, and drinking in hazardous situations) compared to females (Schuckit, Daeppen, Tipp, Hesselbrock, \& Bucholz, 1998; Scott, et al., 2008), while ages of onset for alcohol problems varied based on the population studied. Scott et al (2008), for example, found few differences in the age of occurrence of alcohol problems between male and female Blacks, while Schuckit et al. (1998) reported older ages of occurrence for females versus males for most alcohol problems in a predominately White sample. Comparisons showed a higher prevalence of alcohol problems for White adults versus Black adults with few exceptions, with a later age of onset for Blacks for getting into alcohol-related fights and losing control of problem drinking (Scott, et al., 2008).

Among adolescent drinkers, Wagner et al. (2002) found a higher prevalence of most alcohol abuse and dependence symptoms (6 of 11) in Whites compared to Blacks. Few differences were reported between males and females ( 2 out of 11), with higher rates for males only in drinking in hazardous situations and alcohol-related legal problems. Harford et al. (2005) found both gender and race differences in the rates of alcohol abuse and dependence symptoms in the general population, but these differences varied by age group. Young 
adolescent males and females (aged 12-17 years) did not vary in the prevalence of alcohol symptom criteria, whereas males in all older age groups (e.g., 18-23, 24-29, 30-49, and $\geq$ 50) reported higher proportions of symptoms than females. Furthermore, Black males and females in younger age groups (e.g., 12-17 and 18-23) were less likely to report most individual alcohol symptoms compared to White males and females, although this difference may change in older age groups. Alcohol problems for Blacks are highest among those in their 30s, while for Whites alcohol problems are associated with younger drinkers and a youthful lifestyle (Caetano, 1984; Caetano \& Herd, 1984; Muthen \& Muthen, 2000).

\subsection{Other indicators of risk for alcohol problems}

Several heuristic models for predicting drinking behaviors and related problems among adolescents and young adults have been proposed. These models focus on risk factors associated with pathological alcohol use, including low school success, a family history of alcoholism, family conflict/disorganization, childhood behavior problems, relationships with substance abusing peers, and positive expectancies for the effects of alcohol on behavior, cognition and affect (Chassin \& DeLucia, 1996; V. M. Hesselbrock \& Hesselbrock, 2006; Sher, Grekin, \& Williams, 2005). The nature of the risk for developing alcohol problems due to a family history of alcoholism appears to be both genetic and environmental (V. M. Hesselbrock \& Hesselbrock, 2006). Parents may influence adolescent alcohol use through modeling, approval of drinking, and providing access to alcohol (Brown et al., 2008; Donovan, 2004). Children from families characterized by high stress and family dysfunction are also at greater risk for developing alcohol problems (Kumpfer, 1998). Zucker (2008), in a review of longitudinal studies, identified a consistent relationship for aggressiveness and other childhood conduct problems with problem drinking. Furthermore, a relationship between early drinking behaviors and later drinking problems was dependably replicated. For example, based on Monitoring The Future longitudinal data obtained on a national sample of adolescents, drinking behavior at age 18 predicted later drinking outcomes from ages 22 to 35 (Zucker, 2008). An earlier age of drinking onset is also a strong predictor of the increased risk for the development of an alcohol use disorder and alcohol problem severity (Grant, Stinson, \& Harford, 2001; Hingson, Heeren, \& Winter, 2006a; Muthen \& Muthen, 2000).

The current study aims to expand previous analyses of individual alcohol problems across race and gender groups. The literature for adolescents and young adults on this topic is relatively small, particularly when compared with empirical findings for gender and racial group differences in adolescent/young adult drinking behaviors. We tested race and gender differences in the prevalence and age of onset of individual alcohol problems, as well the number of problems reported by subjects in a community sample of Black and White young adult drinkers. This study included data collected from biological fathers and their adolescent/young adult offspring; adolescent data was collected over a 10-year period. We hypothesized that Whites and males would generally have a higher prevalence and earlier age of onset of individual alcohol problems compared to Blacks and females, respectively. Whites and males were also expected to report more alcohol problems (i.e., greater alcohol problem severity). Other possible predictors of alcohol problem severity examined included demographics, family environment, childhood conduct problems, and alcohol use behaviors and expectancies. Examining race and gender group differences in relation to individual alcohol problems may be important for recognizing early symptoms for pathological alcohol use in diverse young adult populations. The number of alcohol problems reported by young adults provides information about the overall severity of alcohol problems across ethnic and gender groups. The identification of other predictors of alcohol problem severity may help to create more targeted and effective interventions for young adults who are at risk for alcohol use disorders. 


\section{Method}

\subsection{Participants}

This sample of young adults $(N=166)$ was between the ages of 23 and $29(M=25.89, S D=$ 1.53), and was $59.6 \%$ female. All subjects self-identified their racial group as either White $(77.7 \%, n=129)$ or Black $(22.3 \%, n=37)$. Subjects were defined as drinkers if they met 1 of 3 lifetime criteria: 1) consuming 4 or more drinks in a 24-hour period, 2) drinking to intoxication on at least one occasion, and 3) drinking at least once a month for 6 months or more. White and Black young adults did not differ in terms of their gender composition (59.5\% vs. $59.7 \%$, respectively).

Adolescent and young adult at risk subjects were recruited from the greater Hartford metropolitan area, CT as a part of a larger longitudinal study (RISK project). This larger study was designed to follow offspring of alcohol and drug dependent fathers over time as they progressed from adolescence to adulthood. Offspring whose biological parent(s) have a history of alcohol/substance dependence are at greater risk for pathological alcohol use (Chassin, Rogosch, \& Barrera, 1991; Sher, Walitzer, Wood, \& Brent, 1991). Most subjects (76.1\%) recruited for the RISK project had initiated alcohol use at baseline, but no subjects met diagnostic criteria for alcohol dependence. Subjects were interviewed 3 times at fiveyear intervals between 1993 and 2009 to assess the effect of paternal alcoholism on offspring alcohol use behaviors and related problems.

A total of 338 subjects completed a baseline interview for the RISK study. Follow up interviews were completed with 281 subjects at Time 2 and 209 subjects at Time 3. We selected the current sample of White and Black drinkers $(n=166)$ from interviews conducted at Time 3 of the longitudinal study. Nondrinkers $(n=22)$ were excluded from the sample. Hispanic subjects and those categorized as other race were excluded due to their small sample size $(n=18)$. Three subjects $(n=3)$ over the age of 30 years at Time 3 were excluded. The current sample was between the ages of 14 and 19 at the time of the baseline assessment; this age range represents an important period for high risk drinking behaviors and in the development of early alcohol use disorder symptoms (Chen, et al., 2004/2005; Martin \& Winters, 1998).

\subsection{Procedures}

Adolescent subjects were initially recruited through outreach to middle schools, high schools, the YMCA/YWCA, police athletic leagues, and teen centers. Additional recruitment efforts included advertisements in local newspapers and presentations at adult alcohol and drug treatment centers to identify parents with eligible children. A potential subject or his/her parent was invited to contact a research assistant for additional information. Adolescents who had a history of DSM-III-R alcohol or drug use disorders at the time of recruitment were excluded from the study to test the effect of paternal alcoholism on the development of pathological alcohol use in offspring previously unaffected by an alcohol use disorder. Adolescents with a maternal history of alcohol or drug dependence were excluded to minimize the possible influence of prenatal alcohol exposure on study findings. Children diagnosed with Fetal Alcohol Spectrum Disorder (FASD) often experience later alcohol and drug problems and other challenges (e.g., mental health problems, disrupted school experience, employment problems, and trouble with the law) associated with an increased risk for alcohol use disorders (NIAAA, 2005). Eligible subjects and their biological fathers signed consent forms approved by the University of Connecticut Health Center s Institutional Review Board. Fathers were interviewed at baseline (Time 1); adolescents were interviewed at the 3 different time points. A research assistant re-contacted 
subjects approximately five and ten years after Time 1 to complete follow-up interviews.

The completion rate was $83 \%$ at Time 2 and $72 \%$ at Time 3 .

\subsection{Measures}

The longitudinal nature of the data used for this study allow for the examination of Time1, Time 2 and Time 3 variables as predictors of Time 3 alcohol problem severity. Paternal alcohol dependence was assessed at Time 1 and current drinking behaviors and alcohol expectancies were measured at Time 2 . All other variables, including individual alcohol problems were measured at Time 3.

2.3.1. Alcohol problems-Alcohol problems were defined by DSM-III-R (Diagnostic and Statistical Manual of Mental Disorders, Third edition, Revised; American Psychiatric Association, 1987) alcohol abuse and dependence symptoms and other non-diagnostic alcohol-related problems obtained through the Semi-structured Assessment for the Genetics of Alcoholism (SSAGA-I). Thirteen (13) separate alcohol problems were examined, including: 1) drinking/drunk while in hazardous situations, 2) black outs due to drinking, 3) tolerance to alcohol, 4) consider self an excessive drinker, 5) arguments while drinking, 6) started drinking at times not intended, 7) felt guilty about drinking, 8) got drunk when didn $\mathrm{t}$ want to be, 9) early morning drinking, 10) hit and threw things while drinking, 11) physical fights while intoxicated, 12) wanted to quit or cut down 3 or more times, and 13) objections about drinking from family, friends, or medical doctor. Subjects were first asked whether they experienced each alcohol problem and if yes, were asked their age at the first appearance of that problem. The 13 alcohol problems were summed (0-13) to create the alcohol problem severity variable. The SSAGA-I is a structured psychiatric interview that covers the major Axis I diagnostic disorders in the DSM-III-R. It has good test-retest reliabilities ( $\kappa=.70$ to .84$)$ and shows good concurrent validity $(\kappa=.63$ to .71$)$ for life-time alcohol use disorder and antisocial personality disorder diagnoses (Bucholz, et al., 1994;M. Hesselbrock, Easton, Bucholz, Schuckit, \& Hesselbrock, 1999).

2.3.2. Demographics-Each subject self identified their current age and racial background, coded as 0 for Black and 1 for White. Gender ( 0 female; 1 male) was recorded as observed by a research assistant during the interview. Subjects were categorized for their level of education as completing (1) versus not completing high school (0) based on the highest grade in school they completed at Time 3 .

2.3.3. Childhood household conflict-Subjects were asked about their childhood home environment. They rated the level of conflict or tension in their household when they were between $6-13$ years of age. A lower score on this family environment item (1-4; a lot, some, a little, none) identified more childhood household conflict.

2.3.4. Paternal alcohol dependence-All fathers completed the SSAGA-I at Time 1 and a lifetime DSM-III-R alcohol use disorder diagnosis was determined. The presence of a positive lifetime DSM-III-R diagnosis of alcohol dependence defined paternal alcoholism ( 0 no paternal alcohol dependence; 1 paternal alcohol dependence).

2.3.5. Conduct problems-Thirteen (13) lifetime DSM-III-R childhood conduct disorder symptoms from the SSAGA-I were summed to define conduct problems, including 1) stolen money or things more than once, 2) ran away from home overnight at least twice, 3) often lies, 4) deliberately set fires, 5) often truant from school, 6) broken into someone else s property, 7) deliberately destroyed other s property, 8) physically cruel to animals, 9) forced someone into sexual activity, 10) used a weapon in more than one fight, 11) often 
initiates physical fights, 12) stolen with confrontation, and 13) physically cruel to people. Only symptoms not occurring under the influence of alcohol or drugs were counted.

2.3.6. Age of first intoxication-Subjects were asked how old they were the first time they got drunk (i.e., "your speech was slurred or you were unsteady on your feet").

2.3.7. Earlier (Time 2) drinking behaviors-At Time 2, each subject was asked to describe his/her current drinking behaviors, including 1) the number of days a week he/she drinks beer wine or liquor, i.e., frequency of drinking, and 2) the number of drinks he/she consumes on a typical occasion, i.e., quantity of drinks. The variable peer intoxication days was based on the drinking behaviors of each subject s self-identified best friend. Subjects were asked to assess the number of days a week their best friend gets drunk.

2.3.8. Alcohol expectancies at Time 2-The Alcohol Expectancies Questionnaire for Adolescents (AEQ-A; Brown, Christiansen, \& Goldman, 1987) was used to assess beliefs about the expected positive and negative effects of alcohol. The AEQ-A s global positive subscale (scored: 0-17) was utilized, and involved yes/no answers to such questions as, "drinking makes me feel good" and "I like the taste of some alcoholic beverages." The AEQ-A has acceptable internal consistency ( $\alpha=.47$ to .82 ) and test-retest reliability (global positive subscale: $r=.61$ ) and shows convergent validity with drinking behaviors (Brown, et al., 1987).

\subsection{Data analysis}

2.4.1. Bivariate statistics-Statistical analyses were conducted using SPSS Versions 17.0 and 18.0 (SPSS Inc., Chicago, IL). Chi-square $\left(\chi^{2}\right)$ statistics examined the proportion of subjects experiencing each alcohol problem by race and gender. Independent $t$ tests assessed race and gender differences in the age of first appearance of individual alcohol problems. The Levene's test was used to check the homogeneity of variance assumption; when violated the unequal-variance $t$ statistic was reported. The probability value of $p<.05$ determined statistical significance for all analyses.

2.4.2. Linear regression-A hierarchical linear regression analysis was conducted to test race and gender differences in alcohol problem severity, as well as the effects of other predictive factors in this sample of young adults. At Step 1, demographic variables (i.e., race, gender, age and education) were examined as predictors of alcohol problem severity. At Step 2, other predictors, including family environment variables (i.e., paternal alcoholism and childhood household conflict), conduct problems, age of first intoxication, and earlier (Time 2) drinking behaviors (i.e., frequency of drinking, quantity of drinks, and peer intoxication days) and positive alcohol expectancies, were assessed along with demographic variables. The interaction terms of race and gender, race and age, and gender and age were added at Step 3. At each step, all variables were entered simultaneously, assessing the contribution of each independent variable after controlling for the other variables in the model. Variables were screened for multicollinearity, normality and linearity prior to model testing; no transformations were required.

\section{Results}

\subsection{Sample characteristics}

Table 1 presents characteristics for the sample disaggregated separately by race and gender. Subjects age did not vary by race or gender. The majority of subjects finished high school, although Blacks, $\chi^{2}(1)=13.54, p<.001$, were significantly less likely to complete high school compared to Whites. Approximately half of the subjects reported experiencing little 
or no household conflict or tension in their childhood family environment. At Time 1, the majority of subjects were living with their mother and biological father; few subjects reported never being able to see their father.

Both young adult subjects and their biological fathers were evaluated for psychiatric disorders according to the DSM-III-R, with childhood conduct disorder in at risk subjects and alcohol dependence in fathers being important for this study of alcohol problems. Paternal alcoholism was lower among Black subjects, $\chi^{2}(1)=8.71, p=.003$, and for female subjects, $\chi^{2}(1)=12.10, p=.001$. The majority of young adult subjects reported 1 or more lifetime conduct problems, with females reporting significantly fewer conduct problems than males, $t(122)=4.56, p<.001$. The frequency of conduct problems did not vary by race.

Subjects self reported their own and peer drinking behaviors, including alcohol use and alcohol expectancies at Time 2. Most subjects first drank to intoxication during their adolescent years, with Blacks being significantly older than Whites, $t(49)=-2.47, p=.017$. Subjects reported drinking at an average rate of 1 to 2 days a week; this varied significantly by gender, but not by race. Males reported more drinking days than females, $t(149)=2.71, p$ $=.007$, and consumed more drinks per occasion, $t(89)=3.08, p=.003$. Whites consumed more drinks per occasion compared to Blacks, $t(61)=2.96, p=.004$. Positive alcohol expectancies did not vary by race or gender. Subjects described the drinking behavior of their best friend (peer). He/she was estimated to get drunk an average of 0.69-1.39 days per week; more days of peer intoxication were estimated by males than females, $t(92)=3.04, p$ $=.003$.

\subsection{Alcohol problems}

The most common alcohol problems reported by this sample of young adults were driving or being drunk in hazardous situations, blackouts due to drinking, and tolerance to alcohol. The prevalence of individual alcohol problems (See Table 2) did not vary by race with one exception; fewer Blacks than Whites, $\chi^{2}(1)=4.02, p=.045$, considered themselves to be excessive drinkers. Males reported higher rates of driving or being drunk in hazardous situations, $\chi^{2}(1)=5.04, p=.025$, blackouts due to drinking, $\chi^{2}(1)=5.21, p=.023$, tolerance to alcohol, $\chi^{2}(1)=11.60, p=.001$, early morning drinking, $\chi^{2}(1)=14.73, p<.001$, hitting and throwing things, $\chi^{2}(1)=5.07, p=.024$, and physical fights, $\chi^{2}(1)=16.54, p<.001$, while drunk. Further, more males than females wanted to quit or cut down their drinking, $\chi^{2}(1)=5.74, p=.017$, and considered themselves to be an excessive drinker, $\chi^{2}(1)=5.92, p$ $=.015$.

All alcohol problems first occurred in this sample while subjects were in their late teens and early 20s. Drinking problems with an earlier occurrence included objections by family, friends and/or a medical doctor about his/her drinking $(M=18.52, S D=3.65)$ and blackouts $(M=19.16, S D=3.05)$. Wanted to quit or cut down 3 or more times $(M=21.69, S D=2.75)$ had the latest age of onset. Table 3 compares the age of onset for alcohol problems by race and gender. Males and females did not vary significantly in their age of onset for alcohol problems. The onset of alcohol problems was generally later for Blacks than Whites. Blacks experienced a significantly later age of first occurrence for drinking in hazardous situations, $t(87)=-2.79, p=.007$ and early morning drinking, $t(31)=-2.45, p=.020$. Blacks were also older when arguments, $t(52)=-3.42, p=.001$, and physical fights, $t(28)=-3.70, p=$. 001 while drinking first occurred.

\subsection{Hierarchical regression}

Table 4 displays the unstandardized regression coefficients $(B)$ and the $R^{2}$ statistic for each step in the hierarchical analysis. The regression models tested at each step were significantly 
different from zero at $p<.001$. The model at Step 1, which included race, gender and other demographics, predicted $14.5 \%$ of the variance $\left(R^{2}\right)$ in alcohol problem severity. At Step 2, the percentage of variance explained increased to $46.7 \%$, with the addition of family environment variables, childhood conduct problems, drinking behaviors, and alcohol expectancies, $F(8,135)=10.23, p<.001$. Total variance explained increased to $49.7 \%$ at Step $3, F(1,134)=7.94, p=.006$, with the addition of the race $\mathrm{x}$ gender interaction term. The interactions between race and age and between gender and age did not reliably predict alcohol problem severity after controlling for the other variables.

At Step 1, significant gender differences in alcohol problem severity were found. Males $(M$ $=4.63, S D=3.63$ ) experienced more alcohol problems than females (Females: $M=2.79, S D$ $=2.94), t(1)=3.22, p=.002$. Blacks $(M=2.86, S D=3.09)$ and Whites $(M=3.72, S D=$ 3.41) did not reliably vary in their severity of reported alcohol problems, $t(1)=1.87, p=$. 063. Other demographic predictors at Step 1 included education and age. Young adults who completed high school experienced fewer alcohol problems, $t(1)=-2.83, p=.005$. Age did not predict the severity of alcohol problems after considering the contribution of other variables, $t(1)=1.73, p=.086$. Male gender, $t(1)=2.02, p=.045$, and having completed a high school education, $t(1)=-2.13, p=.035$, predicted alcohol problem severity even after family environment, conduct, and alcohol variables were added to the model at Step 2; other demographic variables remained non-significant. Greater household conflict during childhood, $t(1)=-3.12, p=.002$, and paternal alcohol dependence, $t(1)=3.36, p=.001$, predicted more alcohol problems. Three alcohol use variables (i.e., age of first intoxication, the frequency of drinking, and positive alcohol expectancies at Time 2) significantly contributed to the prediction of Time 3 alcohol problem severity. Age of first intoxication was inversely associated with the number of alcohol problems, $t(1)=-2.79, p=.006$, e.g., subjects with an earlier age of first intoxication experienced more severe alcohol problems. Subjects with more frequent drinking days per week at Time 2, $t(1)=2.83, p=.005$, and with more positive expectancies for the effects of alcohol, $t(1)=3.33, p=.001$ at Time 2 also experienced more alcohol problems at Time 3 . Childhood conduct problems was not a significant predictor of alcohol problem severity in the Step 2 model, $t(1)=-0.34, p=.734$. Subjects quantity of drinking on typical occasions, $t(1)=0.52, p=.603$, and the number of peer intoxication days, $t(1)=-0.31, p=.758$, at Time 2 were not significant predictors of Time 3 severity of alcohol problems.

At Step 3, the interaction between race and gender was a reliable predictor of alcohol problems, $t(1)=2.82, p=.006$. Post hoc analyses (See Figure 1) identified White males with the highest level of alcohol problem severity $(M=5.19, S D=3.54)$, while Black males $(M=2.67, S D=3.37)$, White females $(M=2.73, S D=2.95)$ and Black females $(M=3.00$, $S D=2.96$ ) similarly had a lower level of alcohol problem severity. The relationships of other variables in the model to Time 3 alcohol problems were relatively unchanged with the addition of the race-gender interaction term. The exception was the variable male gender, which no longer predicted alcohol problem severity after accounting for other variables.

\section{Discussion}

Our findings provide important comparisons across race and gender in the prevalence and age of onset of individual alcohol problems for young adult drinkers. Males compared to females reported a higher prevalence of most alcohol problems, and showed greater alcohol problem severity, even after considering the effects of the family environment, conduct problems, and drinking behaviors. This finding is consistent with earlier studies of older adult samples (Harford, et al., 2005; Schuckit, et al., 1998), but may contradict studies of individual alcohol problems with younger age groups. Wagner et al. (2002) and Harford et al. (2005) reported few gender differences in alcohol problem rates for adolescents, although 
these study samples were more heterogeneous and included Hispanic subjects which may account for the discrepancy. Males relative to females in the current sample also experienced more risk factors for developing alcohol problems (e.g., males reported more paternal alcoholism and more frequent drinking). Higher rates of heavy and risky drinking in adolescent and young adult males compared to females are consistently found in national samples (Chen, et al., 2004/2005; Chen, et al., 2009; SAMHSA, 2007). We identified White males as a particularly high risk subgroup is this young adult sample, experiencing more severe alcohol problems than other race-gender subgroups.

Schuckit et al. (1998) theorized that differences between males and females in the prevalence and age of onset for alcohol problems reflect the gender roles in the larger society, rather than unique aspects of the course of alcoholism. Similar to patterns for men in the general population, we showed that males had significantly higher rates of drinking in hazardous situations, engaging in violent behavior while drinking, and experiencing problems related to excessive alcohol use compared to females. Conversely, we found no significant differences between males and females in the age of first occurrence for individual alcohol problems. Scott et al. (2008) reported comparable findings between males and females among Black adults. Schuckit et al. (1998) did report later ages of onset for alcohol related social and interpersonal problems and loss of control of drinking for women compared to men, but noted that these differences were relatively small, between 1 to 2 years in magnitude. The ages of first occurrence for most alcohol problems in this young adult sample occurred less than 1 year apart for males and females.

Greater proportions of Whites compared to Blacks were expected to experience individual alcohol problems, as supported by other studies (Harford, et al., 2005; Scott, et al., 2008; Wagner, et al., 2002). However, we found that Blacks and Whites had similar rates of individual alcohol problems (with one exception) and that the level of alcohol problem severity between racial groups did not differ. It could be hypothesized that emerging adulthood represents a transition period between adolescence and adulthood, with comparable rates of alcohol problems between racial groups. Wagner et al. (2002) and Harford et al. (2005), for example, reported more alcohol problems for Whites than Blacks in adolescence, while the reverse was found in adult drinkers - with a greater risk for alcohol problems in Blacks than Whites (Mulia, Ye, Greenfield, \& Zemore, 2009). Similarly, Muthen and Muthen (2000) reported a lower level of alcohol problems for Blacks versus Whites at age 25, but by age 37 years, Blacks had higher levels of alcohol problems than Whites. Scott et al. (2008) alternatively found higher alcohol problem rates for Whites than Blacks among older adults, but this finding may be more specific to their study sample of alcohol dependent individuals. We found that Whites in this sample were significantly more likely than Blacks to consider them self an excessive drinker. This difference may be a correlate of racial group differences in drinking behaviors, as Whites reported drinking significantly larger quantities per occasion than Blacks. Cultural differences in norms and attitudes toward drinking may also affect an individual s definition of excessive drinking. However, Blacks have generally been shown to have more conservative drinking attitudes than Whites (Herd, 1997; Herd \& Grube, 1996).

The effect of Black conservative drinking norms on drinking behaviors may be more directly linked to racial group differences in the age of first appearance of alcohol problems, but this was not examined for this study. We found that Blacks compared to Whites had a later age of onset for some alcohol problems (i.e., hazardous use, arguments and physical fights while drinking, and early morning drinking). Scott et al (2008) also reported a later age of first occurrence for alcohol-related physical fights and the loss of control of problem drinking for Blacks than Whites. In the current study significant racial group differences in the onset of alcohol problems correspond with the older age of first intoxication for Blacks 
relative to Whites, but this may also reflect variations in socioeconomic status (SES). The hazardous use of alcohol, for example, which primarily involves driving while or after drinking, is associated with higher income (Keyes \& Hasin, 2008). Many socioeconomic indicators are frequently unequal across racial groups. This study also showed that Blacks had a significantly lower rate of high school completion compared to Whites. Nationally, Blacks relative to Whites have lower median family incomes, educational attainment, and wealth (Jackson \& Williams, 2006), SES indicators that may reduce their access to driving a car. We did not consider indicators of income and wealth in the current study, but their inclusion may be important for future research related to race and the age of alcohol problem onset.

Consistent with previous studies of adolescent and adult alcohol use behavior (Harford, et al., 2005; Martin \& Winters, 1998; Wagner, et al., 2002), hazardous use, tolerance and blackouts were common alcohol problems in this sample of young adult drinkers. Langenbucher and Chung (1995) and Martin et al. (1996) described three stages of alcohol symptom onset. Earlier onset problems (i.e., objections about drinking by family/friends/ medical doctor and blackouts due to drinking) were characteristic of the excessive drinking and associated social problems in the first stage of alcohol symptom onset. The alcohol problem with the latest age of onset was wanted to quit or cut down 3 or more times, possibly indicating impaired control over drinking and the development of an alcohol dependence disorder (i.e., stage 2). Alcohol problems experienced by the current sample may illustrate stages 1 and 2 . Alcohol problems associated with stage 3 , including withdrawal symptoms or giving up activities for drinking were not examined for the current study. It is also important to note that some investigators caution that alcohol symptoms reported by adolescent and young adult drinkers may not be equivalent to those reported by adult alcoholics (Caetano \& Babor, 2006; Martin \& Winters, 1998). Tolerance to alcohol may represent a normal developmental phenomenon in young drinkers that is not equivalent to the chronic diagnostic criterion for alcohol dependence. Blackouts are often associated with binge drinking, a common drinking pattern for young adults.

Hierarchical linear regression models identified gender, family environment, and alcohol use and expectancies as important predictors of alcohol problem severity. Subjects with family environments characterized by paternal alcoholism and increased household conflict reported more severe alcohol problems after considering the contribution of other variables. A family history of problem drinking and an early onset of drinking have been identified by Muthen and Muthen (2000) and others as strong predictors of alcohol problem severity in young adults. Our findings for the association of positive alcohol expectancies and younger first intoxication with greater alcohol problem severity, support earlier findings on the inverse relationship between early onset use and later alcohol use disorders (Grant, et al., 2001; Hingson, et al., 2006a) along with the role of alcohol expectancies in predicting alcohol related problems in younger samples (Evans \& Dunn, 1995; Sher, et al., 2005). Similarly, the concept of autostability of drinking behaviors as outlined by Zucker (2008) was supported in this study; the frequency of drinking measured 5 years earlier was a reliable predictor of later alcohol problem severity. However, this relationship between earlier and later drinking behaviors may not persist as these young adults move into adult roles and later adulthood, a transition associated with normative reductions in drinking and alcohol problems (Maggs \& Schulenberg, 2004/2005).

The strengths and limitations of this study should be noted in considering these findings. This study focused on the transition period from early adolescence to young adulthood, a time of increased risk for increasing alcohol use and the initial development of alcohol problems. We examined race and gender differences in relation to reported individual alcohol problems, which have not been well researched in young adult samples. The 
longitudinal prospective nature of the data allowed for the study of several predictive factors occurring during the development of drinking behaviors and their association with later alcohol problem severity, providing a time ordering for variables. However, the smaller sample size of the Black subjects relative to the White sample may have reduced statistical power for detecting additional group differences. The sampling strategy used for recruiting subjects may also limit the generalizability of findings beyond urban areas in the northeastern United States. Findings may also not apply to certain subgroups of young adult drinkers excluded from the study, including those with an early adolescent alcohol dependence diagnosis or a maternal history of alcohol dependence. An early onset of alcohol dependence (i.e., $<18$ years) has been associated with a more severe course of alcohol dependence, including multiple dependence episodes, episodes lasting longer than one year, and more dependence symptoms (Hingson, Heeren, \& Winter, 2006b).

\section{Conclusions}

Examining race and gender group differences in individual alcohol problems may be important for recognizing early symptoms for pathological alcohol use in diverse young adult populations. For this study, important race and gender differences for individual alcohol problems were identified. We found a higher prevalence of drinking in hazardous situations, engaging in violent behavior while drinking, and experiencing problems of excessive alcohol use in males compared to females and a later age of onset for hazardous use, arguments and physical fights while drinking, and early morning drinking among Blacks compared to Whites. Factors contributing to race and gender differences for alcohol problems require further study, but these differences may be theoretically associated with larger societal factors related to gender roles, social norms toward drinking, and socioeconomic status. Among young adults, White males were identified as a particularly high risk group, experiencing more severe alcohol problems than Black males, White females and Black females. These findings are important to consider when designing effective strategies for preventing alcohol problems in young adults and in tailoring programs for specific race and gender groups.

\section{Research Highlights}

- The most common symptoms of pathological alcohol use in this community sample of Black and White young adult drinkers included drinking in hazardous situations, blackouts, and tolerance.

- Males compared to females had a higher prevalence of drinking in hazardous situations, engaging in violent behavior while drinking, and experiencing problems of excessive alcohol use.

- Blacks had a later age of onset than Whites for hazardous use, arguments and physical fights while drinking, and early morning drinking.

- Males showed greater alcohol problem severity compared to females, while alcohol problem severity did not differ between Blacks and Whites.

\section{Acknowledgments}

We would like to acknowledge Cheryl Constantine for her expertise and dedication to the RISK study. This work was supported in part by NIAAA P60-AA-03510 and T32-AA07290. 


\section{References}

American Psychiatric Association. Diagnostic and statistical manual of mental disorders, third edition, revised. Washington, DC: Author; 1987.

Brown SA, Christiansen BA, Goldman MS. The Alcohol Expectancy Questionnaire: an instrument for the assessment of adolescent and adult alcohol expectancies. J Stud Alcohol 1987;48(5):483-491. [PubMed: 3669677]

Brown SA, McGue M, Maggs J, Schulenberg J, Hingson R, Swartzwelder S, et al. A developmental perspective on alcohol and youths 16 to 20 years of age. Pediatrics 2008;121(Suppl 4):S290-310. [PubMed: 18381495]

Bucholz KK, Cadoret R, Cloninger CR, Dinwiddie SH, Hesselbrock VM, Nurnberger JI Jr, et al. A new, semi-structured psychiatric interview for use in genetic linkage studies: a report on the reliability of the SSAGA. J Stud Alcohol 1994;55(2):149-158. [PubMed: 8189735]

Caetano R. Ethnicity and drinking in northern California: a comparison among whites, blacks and Hispanics. Alcohol Alcohol 1984;19(1):31-44. [PubMed: 6497950]

Caetano R, Babor TF. Diagnosis of alcohol dependence in epidemiological surveys: an epidemic of youthful alcohol dependence or a case of measurement error? Addiction 2006;101(Suppl 1):111114. [PubMed: 16930167]

Caetano R, Herd D. Black drinking practices in northern California. Am J Drug Alcohol Abuse 1984;10(4):571-587. [PubMed: 6534185]

Chassin L, DeLucia C. Drinking during adolescence. Alcohol Health and Research World 1996;20(3): 175-180.

Chassin L, Rogosch F, Barrera M. Substance use and symptomatology among adolescent children of alcoholics. J Abnorm Psychol 1991;100(4):449-463. [PubMed: 1757658]

Chen CM, Dufour MC, Yi H. Alcohol consumption among young adults ages 18-24 in the United States: Results from the 2001-2002 NESARC survey. Alcohol Research and Health 2004/2005;28(4):269-280.

Chen, CM.; Hsiao-ye, Y.; Williams, GD.; Faden, VB. Surveillance report \#86: Trends in underage drinking in the United States, 1991-2007. Bethesda, MD: National Institute on Alcohol Abuse and Alcoholism; 2009.

Evans DM, Dunn NJ. Alcohol expectancies, coping responses and self-efficacy judgments: a replication and extension of Copper et al.'s 1988 study in a college sample. J Stud Alcohol 1995;56(2):186-193. [PubMed: 7760565]

Faden VB. Trends in initiation of alcohol use in the United States 1975 to 2003. Alcohol Clin Exp Res 2006;30(6):1011-1022. [PubMed: 16737460]

Grant BF, Stinson FS, Harford TC. Age at onset of alcohol use and DSM-IV alcohol abuse and dependence: a 12-year follow-up. J Subst Abuse 2001;13(4):493-504. [PubMed: 11775078]

Harford TC, Grant BF, Yi HY, Chen CM. Patterns of DSM-IV alcohol abuse and dependence criteria among adolescents and adults: results from the 2001 National Household Survey on Drug Abuse. Alcohol Clin Exp Res 2005;29(5):810-828. [PubMed: 15897727]

Herd D. Racial differences in women's drinking norms and drinking patterns: a national study. Journal of Substance Abuse 1997;9:137-149. [PubMed: 9494945]

Herd D, Grube J. Black identity and drinking in the US: a national study. Addiction 1996;91 (6):845857. [PubMed: 8696247]

Hesselbrock M, Easton C, Bucholz KK, Schuckit M, Hesselbrock V. A validity study of the SSAGA-a comparison with the SCAN. Addiction 1999;94(9):1361-1370. [PubMed: 10615721]

Hesselbrock, VM.; Hesselbrock, MN. Developmental perspectives on the risk for developing substance abuse problems. In: Miller, WR.; Carroll, KM., editors. Rethinking substance abuse: what the science shows, and what we should do about it. New York: Guilford Press; 2006. p. 97-114.

Hingson RW, Heeren T, Winter MR. Age at drinking onset and alcohol dependence: age at onset, duration, and severity. Arch Pediatr Adolesc Med 2006a;160(7):739-746. [PubMed: 16818840]

Hingson RW, Heeren T, Winter MR. Age of alcohol-dependence onset: associations with severity of dependence and seeking treatment. Pediatrics 2006b;118(3):e755-763. [PubMed: 16950966] 
Jackson, PB.; Williams, DR. The intersection of race, gender, and SES: health paradoxes. In: Schulz, AJ.; Mullings, L., editors. Gender, race, class, and health: intersectional approaches. San Francisco: Jossey-Bass; 2006. p. 131-162.

Keyes KM, Hasin DS. Socio-economic status and problem alcohol use: the positive relationship between income and the DSM-IV alcohol abuse diagnosis. Addiction 2008;103(7):1120-1130. [PubMed: 18494841]

Langenbucher JW, Chung T. Onset and staging of DSM-IV alcohol dependence using mean age and survival-hazard methods. J Abnorm Psychol 1995;104(2):346-354. [PubMed: 7790636]

Maggs J, Schulenberg J. Trajectories of alcohol use during the transition to adulthood. Alcohol Research and Health 2004/2005;28(4):195-201.

Martin CS, Langenbucher JW, Kaczynski NA, Chung T. Staging in the onset of DSM-IV alcohol symptoms in adolescents: survival/ hazard analyses. J Stud Alcohol 1996;57 (5):549-558. [PubMed: 8858553]

Martin CS, Winters KC. Diagnosis and assessment of alcohol use disorders among adolescents. Alcohol Health Res World 1998;22(2):95-105. [PubMed: 15706783]

Mulia N, Ye Y, Greenfield TK, Zemore SE. Disparities in alcohol-related problems among white, black, and Hispanic Americans. Alcohol Clin Exp Res 2009;33(4):654-662. [PubMed: 19183131]

Muthen BO, Muthen LK. The development of heavy drinking and alcohol-related problems from ages 18 to 37 in a U.S. national sample. J Stud Alcohol 2000;61(2):290-300. [PubMed: 10757140]

National Institute on Alcohol Abuse and Alcoholism. Social Work Curriculum on Alcohol Use Disorders. 2005. Retrieved August 12, 2007. from http://pubs.niaaa.nih.gov/publications/Social/main.html

National Institute on Alcohol Abuse and Alcoholism. Alcohol research: A lifespan perspective. Alcohol Alert 2008;74:1-5.

O'Malley PM, Johnston LD, Bachman JG. Alcohol use among adolescents. Alcohol Health and Research World 1998;22(2):85-93. [PubMed: 15706782]

Schuckit MA, Daeppen JB, Tipp JE, Hesselbrock M, Bucholz KK. The clinical course of alcoholrelated problems in alcohol dependent and nonalcohol dependent drinking women and men. J Stud Alcohol 1998;59(5):581-590. [PubMed: 9718111]

Scott DM, Williams CD, Cain GE, Kwagyan J, Kalu N, Ehlers CL, et al. Clinical course of alcohol dependence in African Americans. J Addict Dis 2008;27(4):43-50. [PubMed: 19042590]

Sher KJ, Grekin ER, Williams NA. The development of alcohol use disorders. Annu Rev Clin Psychol 2005;1:493-523. [PubMed: 17716097]

Sher KJ, Walitzer KS, Wood PK, Brent EE. Characteristics of children of alcoholics: putative risk factors, substance use and abuse, and psychopathology. J Abnorm Psychol 1991;100(4):427-448. [PubMed: 1757657]

Substance Abuse and Mental Health Services Administration [SAMHSA]. Results from the 2006 National Survey on Drug Use and Health: National findings (Office of Applied Studies, NSDUH series H-32, DHS publication No. SMA 07-4293). Rockville, MD: 2007.

Wagner EF, Lloyd DA, Gil AG. Racial/ethnic and gender differences in the incidence and onset age of DSM-IV alcohol use disorder symptoms among adolescents. J Stud Alcohol 2002;63(5):609-619. [PubMed: 12380858]

Zucker RA. Anticipating problem alcohol use developmentally from childhood into middle adulthood: what have we learned? Addiction 2008;103(Suppl 1):100-108. [PubMed: 18426543] 


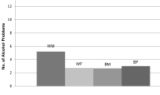

Figure 1.

The effect of race and gender on number of alcohol problems.

Note. $\mathrm{WM}=$ White male $(M=5.19, S D=3.54) ; \mathrm{WF}=$ White female $(M=2.73, S D=2.95)$;

$\mathrm{BM}=$ Black male $(M=2.67, S D=3.37) ; \mathrm{BF}=$ Black female $(M=3.00, S D=2.96)$. 
Table 2

Prevalence of alcohol problems by race and gender $(N=166)$

\begin{tabular}{|c|c|c|c|c|}
\hline \multirow[b]{2}{*}{ Alcohol Problems $c$} & \multicolumn{2}{|l|}{$\underline{\text { Race }}$} & \multicolumn{2}{|l|}{ Gender } \\
\hline & White & Black & Male & Female \\
\hline Drinking/drunk while in hazardous situation & $56.6(73)$ & $43.2(16)$ & $64.2(43)$ & $46.5(46)^{b}$ \\
\hline Black outs due to drinking & $41.1(53)$ & $24.3(9)$ & $47.8(32)$ & $30.3(30)^{b}$ \\
\hline Tolerance to alcohol & $37.2(48)$ & $35.1(13)$ & $52.2(35)$ & $26.3(26)^{a}$ \\
\hline Consider self an excessive drinker & $36.4(47)$ & $18.9(7)^{b}$ & $43.3(29)$ & $25.3(25)^{b}$ \\
\hline Arguments while drinking & $35.7(46)$ & $24.3(9)$ & $40.3(27)$ & $28.3(28)$ \\
\hline Started drinking at times not intended & $24.8(32)$ & $24.3(9)$ & $26.9(18)$ & $23.2(23)$ \\
\hline Felt guilty about drinking & $24.8(32)$ & $18.9(7)$ & $20.9(14)$ & $25.3(25)$ \\
\hline Got drunk when didn't want to be & $22.5(29)$ & $24.3(9)$ & $28.4(19)$ & $19.2(19)$ \\
\hline Early morning drinking & $20.9(27)$ & $16.2(6)$ & $34.3(23)$ & $10.1(10)^{a}$ \\
\hline Hit and threw things while drinking & $21.7(28)$ & $13.5(5)$ & $28.4(19)$ & $14.1(14)^{b}$ \\
\hline Physical fights while intoxicated & $19.4(25)$ & $13.5(5)$ & $32.8(22)$ & $8.1(8)^{a}$ \\
\hline Wanted to quit or cut down 3 or more times & $14.0(18)$ & $21.6(8)$ & $23.9(16)$ & $10.1(10)^{b}$ \\
\hline Objections about drinking from family/ friends/MD ${ }^{d}$ & $17.1(22)$ & $8.1(3)$ & $19.4(13)$ & $12.1(12)$ \\
\hline
\end{tabular}

Notes: \% percentage (sample size);

$a_{p}<.01$

$b_{p}<.05$

${ }^{c}$ Individual alcohol problems are presented in order of highest to lowest prevalence for the full sample;

${ }^{d} \mathrm{MD}=$ medical doctor. 
Table 3

Age of onset for individual alcohol problems: Race and gender comparisons $(N=166)$

\begin{tabular}{llllll}
\hline & Race & & & Gender & \\
\cline { 2 - 3 } Alcohol Problems & White & Black & & Male & Female \\
\hline Drinking/drunk while in hazardous situation & $18.96(2.61)$ & $20.94(2.38)^{a}$ & & $18.79(2.53)$ & $19.80(2.73)$ \\
Black outs due to drinking & $19.30(3.11)$ & $18.25(2.61)$ & $19.90(3.20)$ & $18.40(2.74)$ \\
Tolerance to alcohol & $19.96(2.28)$ & $20.08(2.36)$ & & $20.00(2.49)$ & $19.96(2.01)$ \\
Consider self an excessive drinker & $21.15(3.11)$ & $21.14(3.67)$ & $21.10(3.28)$ & $21.20(3.04)$ \\
Arguments while drinking & $18.78(2.42)$ & $21.89(2.85)^{a}$ & & $18.58(2.80)$ & $19.96(2.53)$ \\
Started drinking at times not intended & $20.39(2.49)$ & $21.11(2.93)$ & $21.10(2.22)$ & $20.08(2.77)$ \\
Felt guilty about drinking & $19.84(4.01)$ & $21.86(3.19)$ & $20.43(3.78)$ & $20.08(4.06)$ \\
Got drunk when didn't want to be & $19.79(2.19)$ & $20.56(2.70)$ & $20.05(2.35)$ & $19.89(2.33)$ \\
Early morning drinking & $20.33(1.92)$ & $22.50(2.17)^{b}$ & $20.74(1.86)$ & $20.70(2.71)$ \\
Hit and threw things while drinking & $19.18(2.25)$ & $20.60(4.16)$ & & $18.79(2.37)$ & $20.21(2.72)$ \\
Physical fights while intoxicated & $18.92(2.53)$ & $23.40(2.07)^{a}$ & & $19.36(3.20)$ & $20.50(2.14)$ \\
Wanted to quit or cut down 3 or more times & $21.39(2.62)$ & $22.38(3.11)$ & $21.69(2.77)$ & $21.70(2.87)$ \\
Objections about drinking from family/friends/MD $d$ & $18.27(3.72)$ & $20.33(3.06)$ & $18.15(2.41)$ & $18.92(4.74)^{c}$ \\
\hline
\end{tabular}

Notes: Mean (standard deviation);

$a_{p<.01 ;}$

$b_{p<.05 ;}$

${ }^{c}$ Equal variance not assumed;

$d_{\mathrm{MD}}=$ medical doctor. 


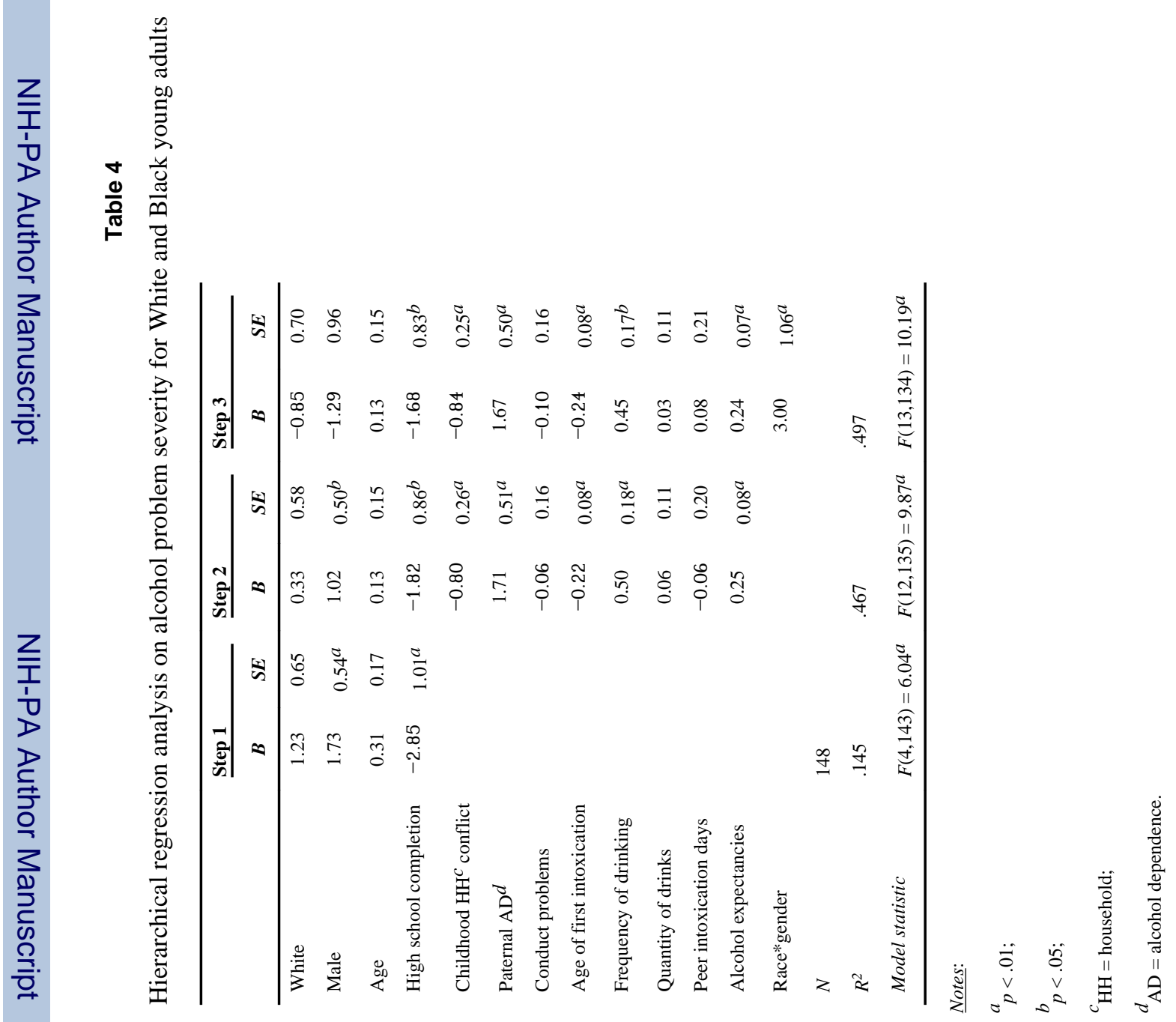

